\title{
A QUALITATIVE EXPLORATION OF HEURISTICS AND COGNITIVE BIASES IN AUDITOR JUDGEMENTS
}

\author{
Agus Fredy Maradona \\ Accounting Program, Faculty of Economics and Business, Universitas Pendidikan Nasional, \\ J1. Bedugul No. 39 Sidakarya, Denpasar 80224, Indonesia \\ Corresponding e-mail: agusfredym@undiknas.ac.id
}

\begin{abstract}
Professional judgement is inherent in financial statement audits because various methods, techniques, or approaches prescribed in auditing standards do not provide auditors with detailed guidance or specific audit criteria. While auditors are expected to exercise their judgements based on careful reasoning, there is a possibility that they do not always follow such an approach and instead make their judgements using heuristics. This study aims to penetrate and reveal whether there are cognitive biases in the judgements of auditors and what heuristics lead to these biases. This study employs a qualitative research design and uses ethnomethodology as a research approach. Data were collected using in-depth semistructured interviews with 15 auditors either as partners, managers, seniors, or juniors at a public accounting firm. Using the heuristic-bias framework as a theoretical lens and based on an analysis involving data condensation, data display, and conclusion drawing and verification, this study identifies five types of biases that auditors can experience: jumping to conclusions, groupthink, representativeness, availability, and anchoring biases. The results of this study present practical implications for auditors, accounting professional associations, public accounting firms, and academic institutions. That is, the findings provide insights for formulating strategies aimed at raising auditors' awareness about possible systematic errors, or biases, in professional judgements when auditors rely on heuristics as a simplifying judgement-making strategy.
\end{abstract}

Keywords: heuristic; bias; audit judgement; audit procedure; ethnomethodology

JEL Classification: M41, M42

Article info:

Received 12 October 2020

Revised 6 December 2020

Accepted 7 December 2020

Available online 18 December 2020

\section{INTRODUCTION}

The use of professional judgment is prevalent in the execution of financial statement audits (Messier et al., 2019). Professional judgement, in this context, refers to the cognitive aspects of auditors' decisions when interpreting and applying various audit procedures and techniques prescribed in auditing standards. The needs for judgments by auditors in the performance of audits stem from the very nature of auditing standards themselves (Knechel, 2013). That is, even though auditing standards provide auditors with guidelines on how to perform audit procedures to achieve the planned audit objectives, these guidelines tend to be general and they do not give the auditors specific criteria or bright-line thresholds that can be used as a basis for making clear-cut decisions (Sin et al., 2015). For example, Standard on Auditing (SA) 320 Materiality in Planning and Performing an Audit requires auditors during the audit planning phase to determine the size of misstatements that will be considered material, but this standard does not provide specific numerical criteria for determining this 
materiality level. Instead, SA 320 asks auditors to exercise their judgements based on their evaluation of relevant financial and non-financial information, the surrounding circumstances, as well as the general business information of an entity. As the use of judgments is required in all auditing standards, this implies that a proper interpretation and application of auditing standards rely substantially on the professional judgments of auditors (Gao and Zhang, 2019). It follows that, because the quality of an audit is determined by a precise application of auditing standards, audit quality is, therefore, determined by the ability of auditors to exercise professional judgment in an appropriate manner when performing audit procedures (Knechel, 2016; Knechel et al., 2013; Wedemeyer, 2010).

The importance of individual judgment in determining the quality of professional work of auditors has led to the emergence of the audit judgment and decision making research field in the late 1970s and has motivated abundant empirical studies ever since (Mactavish et al., 2018; Mala and Chand, 2015). Recent studies in this area have emphasised investigating the factors that determine the judgments of auditors when performing financial statement audits. These studies have shown that the judgment of an auditor is influenced by factors such as emotional intelligence (Yang et al., 2018), intrinsic motivation (Kadous and Zhou, 2019), personal feelings towards clients (Schafer and Schafer, 2019), task complexity (Sanusi et al., 2018), the composition of audit evidence (Lambert and Peytcheva, 2020), types of accounting standards (Tsunogaya et al., 2016), interruptions at work (Kim et al., 2017), obedience pressure from superiors (Tsunogaya et al., 2017), the nature of an auditor's social interactions with their client (Eutsler et al., 2018), and the requirements to report key audit matters (Asbahr and Ruhnke, 2019). Apart from identifying determinants of auditors' judgments, previous studies have also identified the consequences of these judgements. Choudhary et al. (2019), for example, have shown that auditor judgment can lead to differences in audit hours, fees, amounts of audit adjustments, and, even, the number of incidence of restatement of audited financial statements.

Although prior studies have provided important insights on the determinants and consequences of auditor judgments, very few of the recent studies have examined common cognitive biases in the professional judgments of auditors. In the judgement and decision making context, cognitive bias, or simply bias, refers to a systematic error in the judgements of individuals that is caused by the use of simplifying strategies, labelled as mental shortcuts or heuristics, when making judgements (Bazerman and Moore, 2013). The professional judgements of auditors are prone to biases because these judgments are made subjectively by auditors in situations where the auditors have certain direct associations with their clients, and where the auditors face various limitation such as vague auditing standards and limited time (Bettinghaus et al., 2014). Because bias can impair the accuracy of auditors' professional judgments (Bettinghaus et al., 2014; Chang and Luo, 2019), it is therefore crucial to identify the range of biases that can affect the judgments of auditors and the ways through which auditors can overcome these biases.

The importance of examining the biases experienced by auditors has, to some extent, acknowledged in the current auditing literature, although the number of empirical studies on this topic is still limited. For example, (Guiral et al., 2015) examine the impact of expertise on auditors' reporting bias in relation to the going concern of client-companies. A more recent study by Chang and Luo (2019) investigates how the use of data visualisation during an audit process can lead to cognitive biases in the part of auditors. While these studies are interesting since they provide some evidence of determinants of auditors' biases, they do not specifically identify the possible biases that can be experienced by auditors when exercising judgments. Nor do they provide suggestions on how auditors can overcome biases in their professional judgements. Therefore, empirical studies that provide insights about the range of 
biases or heuristics that can affect auditor judgements and their remedies are critically needed.

To fill the gap in the literature, the present study aims to explore biases or heuristics in auditor judgements. Specifically, this study examines the forms of biases that commonly occur when auditors exercise their professional judgments during audit assignments, whether the auditors realise these biases, and, if they do, how the auditors overcome those biases. By focusing on examining the forms of biases in judgments and auditors' awareness of these biases, this study differs from previous studies in two ways. First, unlike previous auditor judgement studies that examine determinants and consequences of variations in auditor judgements (Choudhary et al., 2019; Kadous and Zhou, 2019; Kim et al., 2017; Lambert and Peytcheva, 2020; Sanusi et al., 2018; Yang et al., 2018), this study focuses on examining biases in the judgements of auditors that are caused by the use of mental shortcuts by auditors when making judgements. Second, this study differs from previous audit bias studies (e.g., Chang and Luo, 2019; Guiral et al., 2015) in that this study focuses on exploring the types of biases that are commonly experienced by auditors, particularly in the context of making professional judgements.

\section{LITERATURE REVIEW}

\subsection{Auditor judgment}

Professional judgments are inherent in the work of auditors. As the quality of professional judgments of auditors determines the quality of audit (Knechel, 2016; Knechel et al., 2013; Wedemeyer, 2010), empirical auditing studies have long been interested in identifying the factors that may influence the quality of these judgments. The needs for auditors and other professional accountants to make high-quality judgments when performing their duties has also drawn attention from accounting professional associations (see International Auditing and Assurance Standards Board (IAASB), 2014). For example, in 2012, the Institute of Chartered Accountants of Scotland (ICAS) published a professional judgment framework that aims to provide auditors and other professional accountants with a set of guidelines on how to form appropriate judgements (ICAS, 2012). This framework requires auditors to make professional judgements by following four major principles, namely knowledge gathering and analysis, assessment of accounting and auditing guidance, the process for assessing and challenging a client's judgements, and documentation of judgements.

Previous studies have provided empirical evidence of the factors that influence the judgements of auditors. These studies generally rely on the framework put forward by Bonner (2008), in which it is proposed that auditor judgement is determined by three main factors: person-specific, task-specific, and environmental factors. Accordingly, the existing studies on judgments can be classified along with these three groups of factors. Studies examining the effect of person-specific factors include those examining the effect of emotional intelligence, intrinsic motivation, and personal feelings towards clients on the judgements of auditors (Kadous and Zhou, 2019; Schafer and Schafer, 2019; Yang et al., 2018). The study by Kadous and Zhou (2019), for example, concludes that auditors whose intrinsic motivation is salient are more likely to make judgements more carefully and appropriately compared to auditors whose intrinsic motivation is not salient. Studies examining the influence of taskspecific factors on judgments include the ones investigating the impact of task complexity and the composition of audit evidence (Lambert and Peytcheva, 2020; Sanusi et al., 2018). The study by Sanusi et al. (2018), in particular, shows that auditors tend to make judgments differently when working on more complex audit tasks or when working on less complex audit task. 
Further, studies examining environmental factors have investigated the effects of types of accounting standards, interruptions at work, obedience pressure from superiors, the nature of an auditor's social interactions with their client, the nature of an auditor's social interactions with their client, and the requirements to report key audit matters (Asbahr and Ruhnke, 2019; Eutsler et al., 2018; Kim et al., 2017; Tsunogaya et al., 2016, 2017). These studies have shown that, among others, the judgements of auditors when formed under principles-based accounting standards differ from the judgements formed under principlesbased accounting standards with guidance (Tsunogaya et al., 2016). Also worthy of note that previous studies have also identified the consequences of auditors' judgements, where it has been shown that differences in judgements can lead to variations in audit efforts, fees, audit adjustments, and restatement of financial statements (Choudhary et al., 2019).

What is missing in the existing literature is a focus on heuristics and biases in the judgements of auditors. The literature on judgement and decision-making has suggested that rational judgement and decision making is not always possible, hence at times, individuals will rely on strategies that can simplify the judgment and decision-making process (Ceschi et al., 2019; Cossette, 2014). Nevertheless, empirical studies that provide a thorough examination of the simplifying strategies in making audit judgements and the consequences of these strategies are lacking. This necessitates studies that explore the heuristics used by auditors to simplify their judgment making mechanisms and the biases that may occur in their judgments as a result of these heuristics.

\subsection{Heuristic and cognitive bias}

Making rational decisions is not easy. It involves careful consideration of facts, information, and other relevant inputs, which demands effortful mental activities (Kahneman, 2011). In certain situations, such as the ones where uncertainties are present, the amount of information that should be processed is too large, or are too complex, it is difficult for individuals to make rational judgements based on careful mental processes and, therefore, they rely on heuristics as simplifying strategy (Cossette, 2014). As a simplifying strategy in making judgements, the use of heuristics involves using rules of thumb, relying on stereotypes, and disregarding certain information in order to arrive at a judgment more quickly and effortlessly in comparison to when making judgments using a structured reasoning process (Cossette, 2014). As a strategy, individuals can apply heuristics deliberately or subconsciously (Cossette, 2014).

The literature on heuristic and bias, in general, maintains that the use of heuristics in making judgements is not necessarily bad. In fact, Tversky and Kahneman (1974) who pioneered studies into heuristics, argue that heuristics have certain benefits for individuals when making judgments, particularly by assisting them to make judgements faster. More recent studies such as Gigerenzer and Gaissmaier (2011) and McLaughlin et al. (2014) also propose the same contention by underlining that heuristics present cognitive advantages for decision-makers because they save efforts in making judgments. However, despite acknowledgement of the benefits of heuristics, the literature emphasises that heuristics can lead to systematic errors in individual judgements that are known as biases (Cossette, 2014; McLaughlin et al., 2014; Tversky and Kahneman, 1974).

The perceived potential benefits of heuristics, and the potential judgement failures that these heuristics may lead to, have made heuristics seen as a double-edged sword (Cossette, 2014; Loock and Hinnen, 2015). This has motivated empirical studies to examine the types of heuristics that can be used by individuals when making judgements and what biases these heuristics may lead to (Loock \& Hinnen, 2015). For example, a study by Hussain and Oestreicher (2018) explores how heuristics can lead to cognitive biases in the formulation of medical judgements by medical professionals. Other empirical studies have also examined heuristics and biases in various judgement and decision-making contexts such 
as finance (Otuteye and Siddiquee, 2015), bioethics (Blumenthal-Barby, 2016), and marketing (Nouri et al., 2018), among others.

Although there has been large attention to heuristics and biases in various judgement and decision-making contexts, nevertheless, studies exploring the types of heuristics and biases in the auditing context have yet to be done. Therefore, an exploration of heuristics and biases among auditors is necessary in order to provide a thorough description about what mental shortcuts auditors apply when performing their professional duties and what systematic errors can result from these mental shortcuts.

\subsection{Theoretical framework}

As mentioned previously, this study aims to explore heuristics and biases in the formulation of professional judgements by auditors. To provide guidance for the empirical exploration carried out in this study, a theoretical framework on heuristic and bias is needed. In this study, the heuristic and bias frameworks proposed by Tversky and Kahneman (1974) and Slovic et al. (2007) are combined to develop a theoretical framework that serves as guidance in data collection, data analysis, and discussion of findings. The Tversky and Kahneman's (1974) heuristic and bias framework asserts that in various decision-making situations, individuals rely on heuristic principles to simplify complex tasks into simpler judgmental processes, which, undesirably, may lead to systematic errors, or biases, in individual judgments. This study follows this conception in exploring biases in auditor judgments. That is, in identifying biases that my occur in auditor judgements, this study maintains that the biases originate from several heuristics that are commonly used by auditors when performing their duties. Therefore, to identify those biases, it is important to first recognise the types of heuristics that are common to individuals. Accordingly, this study draws upon the three types of heuristics proposed by Tversky and Kahneman (1974), i.e., the representativeness heuristic, the availability heuristic, and the adjustment and anchoring heuristic, as well as the single additional heuristic proposed by Slovic et al. (2007), that is the affect heuristic, making a total of four types of heuristics.

By employing the four types of heuristics, this study sets out to explore biases that are experienced by auditors when exercising their professional judgements. In particular, this study first identifies the range of biases experienced by auditors, classifies those biases under the four types of heuristics as suggested by Tversky and Kahneman (1974) and Slovic et al. (2007), and examine whether auditors are aware of these biases and, if they do, whether they have strategies to avoid these biases when making judgements.

\section{RESEARCH METHOD}

This study seeks to explore the common biases that can hamper the professional judgements of auditors. Due to the exploratory nature of the study, a qualitative research design was employed. The qualitative design is appropriate for the current study because this research design allows this study to concentrate on a social phenomenon by examining a social setting and the individuals within this social setting, and to focus on how the individuals make sense of their social setting through principles and social practices (Lune and Berg, 2017). The use of a qualitative design also adds an additional novelty value to this study because the majority of prior empirical studies on auditor judgement and decision making are based on the experimental design. The qualitative nature of the present study allows for the discovery of novel evidence that will enrich the findings that have been reported by previous research.

The qualitative research approach utilised in this study is the ethnomethodology approach. Ethnomethodology is a qualitative research approach that seeks to examine how individuals understand their routine or day-to-day activities in order to do things in socially acceptable ways (Patton, 2015). Patton (2015) underlines that the focus of ethnomethodology 
is on understanding the ways by which individuals perform their activities in a setting. These ways of doing things may be taken for granted by the individuals who perform the activities. Nevertheless, ethnomethodology focuses on these trivial ways of doing things to develop an understanding of phenomena and establishing new kinds of way for doing things based on the expectation of the individuals in the setting being studied (Patton, 2015).

The setting of this study is the auditing practice in Indonesia. Accordingly, the components of the audit environment, such as regulations, auditing standards, professional organisations, and the audit profession explored in this study portray the characteristics pertinent to the Indonesia audit practice. Data were collected through in-depth semistructured interviews with relevant informants. A total of 15 informants were interviewed in the data collection stage. Of these 15 informants, two informants were partners in public accounting firms, three informants were auditors at the manager level, six informants were senior auditors, and the remaining four were junior auditors. The informants were from public accounting firms in Jakarta and Bali. These informants were selected due to the relevance of their experience, particularly in making auditor judgements, as well as their knowledge about the challenges in exercising professional judgements in an audit.

Each of the 15 informants was interviewed separately, each in a single interview session. Thus, in total, the study conducted 15 interviews. The interviews were conducted during the period between January and June 2020. Due to the COVID-19 pandemic, some of the interviews, particularly those that were conducted between April and June 2020, could not be conducted face-to-face. Instead, during this period, the interviews were conducted online using the Zoom Cloud Meeting application. The interviews were semi-structured in nature, which aimed at collecting as diverse information as possible from the informants about their experience and knowledge concerning audit judgements. The interview questions focused on exploring the informants' individual experience in making audit judgments, the challenges that they encountered in practice, and the ways through which they solve the challenges that they faced when making professional judgements. The interview questions were also designed to capture the experience of the practising auditors in dealing with errors in their judgements. The interview processes were conducted in accordance with an interview guide which consisted of a set of open-ended questions. These questions were developed based on the theoretical framework employed in this study, i.e., the heuristic-bias framework (Slovic et al., 2007; Tversky and Kahneman, 1974). Nevertheless, this study took a flexible approach in performing the interviews, allowing for the interviews to follow the stories told by the informants and to gather interesting information from them.

Field notes were used to record information from the interviewees. The information gathered in the interviews were subsequently transcribed in word document format. Relevant notes were also used to record insights, emphasises, and other types of reflections of the informants that were not covered by their verbal statements. The data that were collected from the interviews were then analysed iteratively using the interpretative approach (Lune and Berg, 2017). The interpretative approach to qualitative analysis employed in this study follows the three-phase qualitative analysis, as is suggested by Miles et al. (2014). This threephase qualitative analysis consists of data condensation, data display, and conclusion drawing and verification (Miles et al., 2014).

In the data condensation phase, data analysis involves a coding and theming process. That is, the interview transcripts and additional notes were coded manually using a two-cycle coding technique. In the first cycle coding, this study applied a descriptive coding on the interview transcripts. That is, using a manual descriptive coding technique, this study assigned descriptive codes, i.e., words or short phrases, to summarise the basic topic of a passage of qualitative data as appears in the interview transcripts. Next, in the second cycle coding, this study applied a pattern coding technique to identify patterns in the summaries of 
data that resulted from the first cycle coding. The second cycle coding allows this study to perform a theming process, that is a process to identify recurring themes and to construct interrelationship among these themes.

In the data display phase, this study builds upon the themes that were identified in the data condensation phase. Based on these themes, this study subsequently displays the condensed data using a network approach in a graph format, in which codes were arranged in accordance with the identified themes using arrows to show their interrelationships (Miles et al., 2014). In addition to the graph, the data display phase also involves the presentation of narrative or analytic text as an approach to display the data. This narrative aims to elaborate the displayed graphed-data, providing interwoven meanings from which findings and conclusions can be drawn.

Finally, in the conclusion drawing and verification phase, this study performs steps to produce research findings that answer the research questions. This phase covers two main steps: generating meaning and confirming findings. The first step, i.e., generating meaning, is the process through which this study makes sense of the data that have been displayed in the previous phase. This study applied the techniques suggested by Miles et al. (2014) to draw meanings from the displayed data configuration. The techniques include noting patterns and themes, clustering, making comparisons, factoring, building a logical chain of evidence, and making conceptual coherence. Meanwhile, the second step, i.e., confirming findings, is the process through which this study ensures the validity or trustworthiness of the research findings. This study confirms the findings through a triangulation of data source, where information from one informant is corroborated with information from other informants. The findings that have been generated and verified through the conclusions drawing and verification process are then presented as results of this study.

\section{RESULTS AND DISCUSSION}

\subsection{Results}

Based on the analysis of the data, this study identifies various biases that are commonly experienced by auditors when making judgments during the performance of a financial statement audit. The reflections of the interviewees regarding these biases are grouped into four overarching themes, each of which indicates the very nature of a bias and the heuristic from which the bias emerges. These categories of audit judgment biases also reflect the heuristic-bias theoretical framework (Tversky and Kahneman, 1974) employed in this study that maintains that heuristics from which biases occur include the representativeness heuristic, the availability heuristic, the adjustment and anchoring heuristic (Tversky and Kahneman, 1974), and the affect heuristic (Slovic et al., 2007). One important notion appearing from the analysis that warrants consideration is the fact that a bias in the judgments of auditors emerges from heuristics in the judgment making process of individual auditors. This is consistent with Tversky and Kahneman (1974) conception on heuristic and bias in which they propose that heuristics lead to biases in the judgements of individuals. Therefore, when identifying the biases that are experienced by auditors, it is critical to determine which heuristic these biases stem from to better understand the nature of these biases and to examine whether auditors are aware of these heuristics. The following description presents in detail the categories of biases that typically experienced by auditors when making audit judgments.

The first category of bias that emerges from the data analysis is the jumping to conclusions bias. This bias is characterised by the auditors' tendency to make audit decisions based on limited supporting evidence. Audit, by definition, is a process of collecting and evaluating evidence concerning management assertions to determine whether these assertions have been presented in accordance with established criteria. Auditing standards, in particular 
SA 500 Audit Evidence, requires auditors to plan and execute audit procedures that allow them to collect sufficient audit evidence on which the auditors their audit reports. This implies that collecting sufficient and appropriate evidence is a critical component of the audit process. Nevertheless, there are certain situations where auditors depart from this norm, and, instead, rely on limited evidence to make audit conclusions. One of the factors that force auditors to act this way is the time pressure due to perceived limited time to finish an audit. For example, an interviewed auditor revealed the following:

Work overload is common here, particularly at the beginning of the year. A lot of audit assignments need to be completed on time, so we have strict deadlines. This gives us pressure to finish audit tasks a soon as possible, so we will not miss the deadlines. Oftentimes we rely on a minimum amount of evidence and limited audit procedures to make audit conclusions, particularly for repeat clients. We just perform the basics that we consider most relevant as required by auditing standards [Senior Auditor in a small public accounting firm].

The interviewees share the feelings that, oftentimes, there is pressure for them to abruptly meet deadlines of audit completion. The perceived time pressure may still occur even though the overall audit strategies have been planned prior to audit fieldworks. This may result from sudden work overloads, a slow response from clients in providing relevant data, and other unpredictable conditions affecting evidence gathering processes. In this kind of situation, auditors will normally adjust their audit programs to reduce the amount of time needed to complete audit fieldwork and reach audit conclusions. For example, the interviewees revealed that to cope with limited audit time and the need to meet strict deadlines, they had to skip several steps in making audit conclusions, most notably the initial steps where they have to define problems associated with an audit task and to identify alternative techniques for performing the audit task or solutions for certain problems. Consequently, the amount of evidence collected during the process can be minimised. The interviewees emphasised that they took such an approach mainly for repeat clients, where they had had sufficient knowledge about the clients' business and financial reporting environment.

The second category of bias identified in this study is the groupthink bias. This bias is characterised by the auditors' tendency to withhold their personal views concerning an audit issue and, instead, force themselves to agree with group consensuses about the audit issue. The analysis of the data uncovers several causes for the prevalence of this bias among auditors. The most common reason is the reluctance of an auditor, particularly more junior one, to argue with their team leader or more senior members of the audit team if they have different opinions concerning an audit issue. Auditors tend to accept what the team leader says, and more junior auditors incline to listen to the opinions of more senior auditors because they feel obliged to follow the leader of their seniors. As asserted by one of the interviewees:

When evaluating audit evidence or applying an audit procedure, I might have different opinions with other members of the audit team. But most of the time I would not express my differing opinions, particularly when my opinions differ from those of the team leader or others who are more senior because I was afraid it might hamper the audit process or my opinions are wrong. I just follow what the team leader and the seniors say because they know better about auditing, and as a junior, I think that is the right thing to do [Junior Auditor in a large public accounting firm].

Another reason for the prevalence of the groupthink bias among auditors is the perceived need to maintain harmony within a group. Having different opinions or arguing are considered undesirable by some auditors because it is perceived to be against the values of the society they belong to. One interviewee expressed their feelings as follows: 
I think having different opinions will not contribute anything to the team but instead will damage the team. Arguing with other team members, let alone with the team leader, will destroy harmony in our team. I tend to accept what the team leader says or what my senior colleagues think so that I can contribute to maintaining harmony in the team. I believe this is our culture [Junior Auditor in a medium-sized public accounting firm].

The reflection of the interviewees reveals that auditors' tendency to subdue to group opinions and hide their personal thoughts when performing audits grow from their affect heuristic. In this instance, auditors follow their personal feelings regarding the obligation to follow leaders and those who are more senior in terms of age or position in the accounting firm. These feelings prove to be stronger than the auditors' intention to express personal views regarding audit matters. As a result, the auditors will always follow the general views of the team, even though oftentimes the auditors accept these views reluctantly. Most of the time auditors consider the views of their teams to be the most appropriate opinions, the correct audit treatment to an issue, or the most suitable solution to certain problems. An example of the occurrence of the groupthink bias among the interviewees is when deciding on the size of the sample for a substantive test of transactions. Sometimes more junior auditors consider that larger sample size is needed so the audit team can arrive at an audit conclusion with reasonable assurance. Nevertheless, when more senior members of the team or the team decide that the sample size does not need to be increased, the more junior members of the team will rarely question this decision. Instead, they will reconsider their initial opinion and finally accept what the other members of the team say, believing that more senior members of the team and the team leader know better about audit sampling than themselves.

The third category of bias that is identified in this study is the representativeness bias. This bias refers to the auditors' tendency to make audit judgments based on the stereotypes that have previously been formed or that are popular in the professional auditing environment. Auditors tend to rely on these stereotypes to speed up the audit process. As expressed by one interviewee:

When forming opinions or making a judgment in complicated situations, I follow what is common in auditing. I mean, there is a certain consensus in making judgments or performing audit procedures, a consensus that is based on what is generally applied in auditing, things that are considered rules of thumbs. I follow these things to simplify the problems and speed up my work [Manager in a medium-sized public accounting firm].

Auditors incline to follow consensus or stereotypes because this is an easier way to make judgments, particularly when they have limited time and limited judgment basis. Following consensus means that auditors will arrive at their judgments quicker, which is very useful for them when they have to meet short deadlines. Additionally, by sticking to stereotypes, auditors will be able to provide justification for their judgments, citing that the judgments have been based on what is common in auditing practices. Obviously, there is also a propensity among auditors to perceive that what is common must be right.

The interviews revealed several real instances of representativeness bias among auditors. For example, when auditors come across a client company whose main business activities are providing goods or services to government agencies, the auditors will normally consider the audit risk of this company to be higher than that of a similar company whose business operations do not involve serving government institutions. This is because auditors generally believe in stereotypes that companies who deal with government procurements are more likely to pay illegal payments to public officials, which cannot be appropriately reported in financial statements. Another real-world example emanating from the analysis is the situation in which auditors perform a general audit of a company whose financial 
reporting systems are computerised, accounting and finance staff are cooperative, and financial statements are presented neatly. The auditors will have a greater tendency to believe that this company has a strong internal control, robust financial accounting system, and, accordingly, reliable financial information. This tendency occurs because auditors believe in stereotypes that companies with a well-organised financial reporting system, cooperative accounting personnel, and well-presented unaudited financial statements are more likely to have good internal control and fewer errors or fraud in their financial statements. As a result, auditors who perform an audit for such a company tend to set the audit risk of the company to be lower.

The interviewees consider their reliance on stereotypes or conventional perceptions in auditing as an effective way to speed up the audit process. Stereotypes in the auditing practice are considered universal wisdom, just like any wisdom in life in general. Nevertheless, the reliance on this so-called universal audit wisdom also means that there is a risk that auditors may overlook irregularities that can occur across clients.

The fourth category of bias that emerged from the analysis is the availability bias. This bias refers to a condition when auditors tend to assess the probability, frequency, or possible causes of an audit issue based on the extent to which occurrences of the issue or the relevant causes of the issue are readily available in auditors' memory. For the auditors, certain audit-related events that are clear in their minds, trigger emotions, and specific will be more available during a judgment making process than events that are vague, unemotional, and difficult to come up in auditors' minds. As asserted by one of the interviewees:

Past experiences regarding audit circumstances or events, particularly the ones that happen quite frequently are a big influence for me when I make judgments. Those past events come up easily in my mind when I come across a similar event during an audit assignment. When making judgments, I reflect on the way my colleagues or I responded to similar issues that we frequently encountered previously [Senior Auditor in a large public accounting firm].

Several instances of the availability bias that were experienced by the interviewees are quite critical. For example, in an audit of commercial banks, auditors tend to make judgments concerning the appropriate level of loan loss provisions in a commercial bank based on the provision rates that they frequently identified in their previous assignments. In this situation, auditors show a tendency to use their prior knowledge about certain issues as a rule of thumb in evaluating a similar issue. Another example is in the context where auditors assess financial statement preparers' judgment regarding the useful life of fixed assets. Auditors generally judge the appropriateness of the estimated useful life of fixed assets in a client company by comparing to estimations that the auditors frequently encountered in their previous assignments. Auditors tend to believe that the estimation of the useful life of assets that first come to their minds due to the availability of instances is the best estimate, and this estimate is equally appropriate to be applied as a basis in evaluating the estimate made by the management of the client company being audited.

A closer discussion with the interviewees reveals that, in general, auditors consider the availability bias to be a useful audit judgment-making strategy, even though these auditors do not realise that they are under the influence of such a bias. Auditors are fond of using the availability bias strategy when making judgments because it is substantially easier for individuals to recall from their minds instances of events or solutions that have a greater frequency of occurrence in comparison to the ones with a lower frequency of occurrence. Nevertheless, while auditors believe that the availability bias is useful for them, they seem to be unaware of the risk to make incorrect judgments due to the negative impact of the availability bias. As one of the interviewees assert: 
The things that we often see, learn, or encounter will stay in our subconscious minds. This will help us make judgments intuitively. [...] I am a firm believer of intuitive judgment and decision making. [...] I have been in various audit situations where my intuitions worked very well, so I do not think this way of making judgment is wrong [Manager in a medium-sized public accounting firm].

The availability bias is seen by auditors as part of their intuition. Although intuition is an acceptable basis for judgments and decisions, the overreliance on frequently occurring instances as a basis in making judgments have blinded auditors to other relevant information or event that may occur less frequently.

The fifth and last bias identified in this study is the anchoring bias. This bias is characterised by the auditors' tendency to use a piece of information as a focal point and to rely too heavily on this focal point when making judgments. The piece of information that is used as the focal point is usually the first piece of information that is received or gathered by the auditors. Then, the auditors will make subsequent judgments with reference to the first piece of information that they received because that information is the focal point. The analysis of the interview data reveals several reasons as to why auditors have a tendency to over-rely on the first piece of information and use this information as a focal point in exercising their judgments. The most common reason is the habits among auditor to start any audit-judgment-making process by referring to a specific point of reference, normally a numerical reference. One of the interviewees shared their experience as follows:

I normally start my judgment-making process by getting one starting point, normally a number. Then, I will use this number as a reference when making judgments. [...] For example, when deciding on the appropriate amount of allowance for doubtful accounts, I will try to get an average number in the industry and use this as a reference [Senior Auditor in a medium-sized public accounting firm].

The use of numbers as a reference when making judgements seems to be prevalent among auditors. Numbers are considered a clear starting point and any subsequent situation in which judgments are needed are considered easier to evaluate on the basis of these numbers. Apart from the long-time habits of making estimates, it appears that the anchoring bias is prevalent among auditors because auditors believe that making judgments based on a starting point of reference is a systematic and efficient way of making judgments. As put forward by an interviewee:

Judgments cannot be made haphazardly. They cannot be made unsystematically either. An auditor needs a relevant reference, a starting point. This starting point is critical; that is why the auditor has to select this starting point very carefully. This can be a number, a standard, a percentage, or others. Then, after the starting point is found, the auditor can make judgments based on this reference then keep revising the judgments as new information is gathered. This is what I call a systematic way of making good judgments [Partner in a medium-sized public accounting firm].

Further analysis of the interview data confirms that there is a perceived good practice in making judgments among auditors. This perceived good practice dictates auditors to arrive at a judgment by using a systematic way of reasoning and evaluation of information. Interestingly, the so-called systematic way is to start from the point of reference, make an initial judgement based on this point of reference, and continue evaluating the initial judgment based on new information that is collected by the auditors during the application of audit procedures. This approach to making judgments provides auditors with a step-by-step process and, therefore, is normally taught by more senior auditors in a public accounting firm to their juniors or new recruits. As a result, this approach runs from generation to generation of auditors. 
Even though anchoring is considered a bias, auditors seem to be confident when making judgments under the influence of the anchoring bias. This is because auditors perceive that starting judgment-making process by choosing a focal point means that they have carefully planned their decisions. Also, because auditors continue evaluating their initial judgments based on new information, auditors believed that the final judgments that they make are the most appropriate judgments because these judgments have considered all pieces of information gathered along the audit process. Nevertheless, it appears that auditors never consider whether the initial point of reference that they choose in the beginning phase of the judgement-making process is the most appropriate focal point. Auditors interviewed in this study also rarely, if not never, actually check if the evaluation process on the initial judgements have been done sufficiently and appropriately. The auditors simply follow relevant audit procedures, and when there is no new information that is relevant for assessing the existing judgements, then the judgments will not be revised any more.

\subsection{Discussion}

The findings reported in this study provide convincing evidence of the existence of biases in the judgments of auditors. As reported in the previous section, five biases are identified in this study: the jumping to conclusions, the groupthink, the representativeness, the availability, and the anchoring biases. A further analysis using the heuristic-bias framework (Slovic et al., 2007; Tversky and Kahneman, 1974) uncovers the underlying mental shortcuts, or heuristics, that give way to the occurrence of these biases. Also, it is clear from the analysis that auditors often rely on heuristics because they have to make judgements and decisions in situations where uncertainty is present, which is consistent with the conceptual framework proposed by Tversky and Kahneman (1974). In other words, the findings of this study imply that uncertainty gives ways to the use of heuristics in judgment and decision making among auditors, which in turn lead biases in the professional judgements and decisions of these auditors. Specifically, the jumping to conclusion bias as described in the previous section is an audit bias that develops from the affect heuristic, i.e., a heuristic where individuals make judgments under the influence of current emotions or personal feelings (Slovic et al., 2007). In the context of this study, auditors' perceptions that they are under pressure to meet deadlines may lead to the reluctance to make judgments based on careful reasoning. The auditors, instead, rely on their quick, intuitive thinking that is determined by their current emotions. These emotions may include fear of not meeting deadlines, stressed out, or unsatisfaction. Because emotions play a substantial role in judgment formation, auditors may neglect important information that is more rational. This pattern of jumping to conclusion bias in the judgments of auditors are similar to findings of previous behavioural studies (e.g., Jaspersen and Aseervatham, 2017; Johnstone et al., 2017; Lee et al., 2011) which demonstrate that jumping to conclusion bias is quite common among individuals with anxiety or certain other emotions.

An analysis of the interview data reveals that the heuristic that gives way to groupthink bias among auditors is the affect heuristic, particularly the one that comes from the personal values held by these individual auditors. Values are a set of beliefs that determine individual preferences for certain positions, conditions, or state of affairs over others (Hofstede et al., 2010). In the context of the groupthink bias identified in this study, the personal values that trigger the affect heuristic of individual auditors are the value concerning accepting the existence of power distance among individuals and the value of maintaining harmony within a group. The value of accepting power distance manifests itself into the willingness of auditors to accept that certain other individuals possess greater power than themselves. These other individuals may include the team leader, the senior colleagues, or the partners. As a result of the greater power, auditors feel that they must follow the opinions of these other individuals and not their own views. Meanwhile, the value of 
maintaining harmony within a group manifest itself into the auditors' tendency to avoid conflicts within their group. Because having different opinions are perceived to be a conflict, auditors may be reluctant to express different opinions for the sake of avoiding conflicts and maintaining harmony.

A detailed analysis of the interview results uncovers that the representativeness bias clearly develops from the representativeness heuristic. This heuristic works in the subconscious part of auditors' minds where individuals normally store memories on stereotypes. When making judgements, it is much easier for auditors to recall these stereotypes from their memories compared to analysing new situations or information that the auditors are not familiar with. As a result, the auditors are trapped in the representativeness bias. The findings on the existence of the representativeness bias are consistent with findings reported in the existing literature. For example, this study's findings revealing that auditors make audit judgements on the basis of stereotypes in the auditing practice appear to be similar to results reported in prior studies that stereotypes influence individual decisions in the financial investing contexts (Luo, 2013), geographical analysis (Zhang and Zhu, 2019), and the sport and health context (Garber et al., 2019).

Further, the analysis also unveils that the availability bias that is experienced by auditors when they make professional judgments grow from the availability heuristics in these auditors' subconscious minds. This heuristic is characterised by a mental shortcut to use available instances in memories when making judgements or decisions (Tversky and Kahneman, 1974). The tendency of auditors to make judgements using the instances of events or situations that can be easily be recalled from their memories clearly shows that the availability heuristic playas a substantial role in the judgement making process of auditors. The existence of the availability bias in individual judgments is not unique to auditors. The pattern of relationship between the availability heuristic and bias has also been documented in previous studies examining judgments and decisions in various contexts (Davidai and Gilovich, 2016).

Meanwhile, in relation to the anchoring bias, a close analysis of the interview data demonstrates that the anchoring bias in auditors' judgments originate from the use of the adjustment and anchoring heuristic by the auditors when they exercise their professional judgements. It has been argued that individuals typically make judgments by first creating an anchor, or a focal point, i.e. a piece of information that serves as a point of reference for the initial judgement (Givi and Galak, 2019; Tamir and Mitchell, 2013). Individuals will subsequently revise or adjust the initial judgements, resulting in what is called the anchoringadjustment process (Givi and Galak, 2019; Tamir and Mitchell, 2013). The nature of the role of the anchoring bias in auditors' judgment making process identified in this study is similar to the ones reported in previous studies, in which it is found that individuals in different decision situations tend to start their judgment making process by first crated an initial point of reference which is subsequently adjusted to come up with a final judgment (Bouteska and Regaieg, 2019; Xiao, 2020).

It is important to note that while there are five separate biases identified in this study, there is a common feature that is shared by these biases: they distort auditors' professional judgements and decisions. The distortion in judgments and decisions caused by the five biases often occur without auditors knowing that they are under the influence of bias. That is, an auditor may still believe that they are making accurate audit judgements of decisions, even though they are actually, and unknowingly, under the influence of cognitive bias. Although auditors are susceptible to cognitive bias, the existence of audit programs, to some extent, appears to be able to help auditors avoid these judgement traps. Audit programs can help auditors by providing them with decision-making aids that consist of procedures, techniques, or methods that are useful to guide their response to various audit situations. The analysis 
conducted in this study demonstrates that the availability of an excellent audit program is crucial in mitigating the effect of all the five biases identified in this study. However, even the best audit programs cannot completely make auditors immune to cognitive bias. Audit programs cannot be formulated to be extremely detailed because they should be able to be implemented by auditors in various audit situations, and they should allow auditors to improvise depending on the situation.

Taken as a whole, the analysis presented in this study demonstrates a logical relationship between heuristics and biases in the professional judgments of auditors. Figure 1 presents a graphical representation of how cognitive biases experienced by auditors when they make judgments grow from the heuristics that occur in the auditors' judgment and decision-making mechanism.

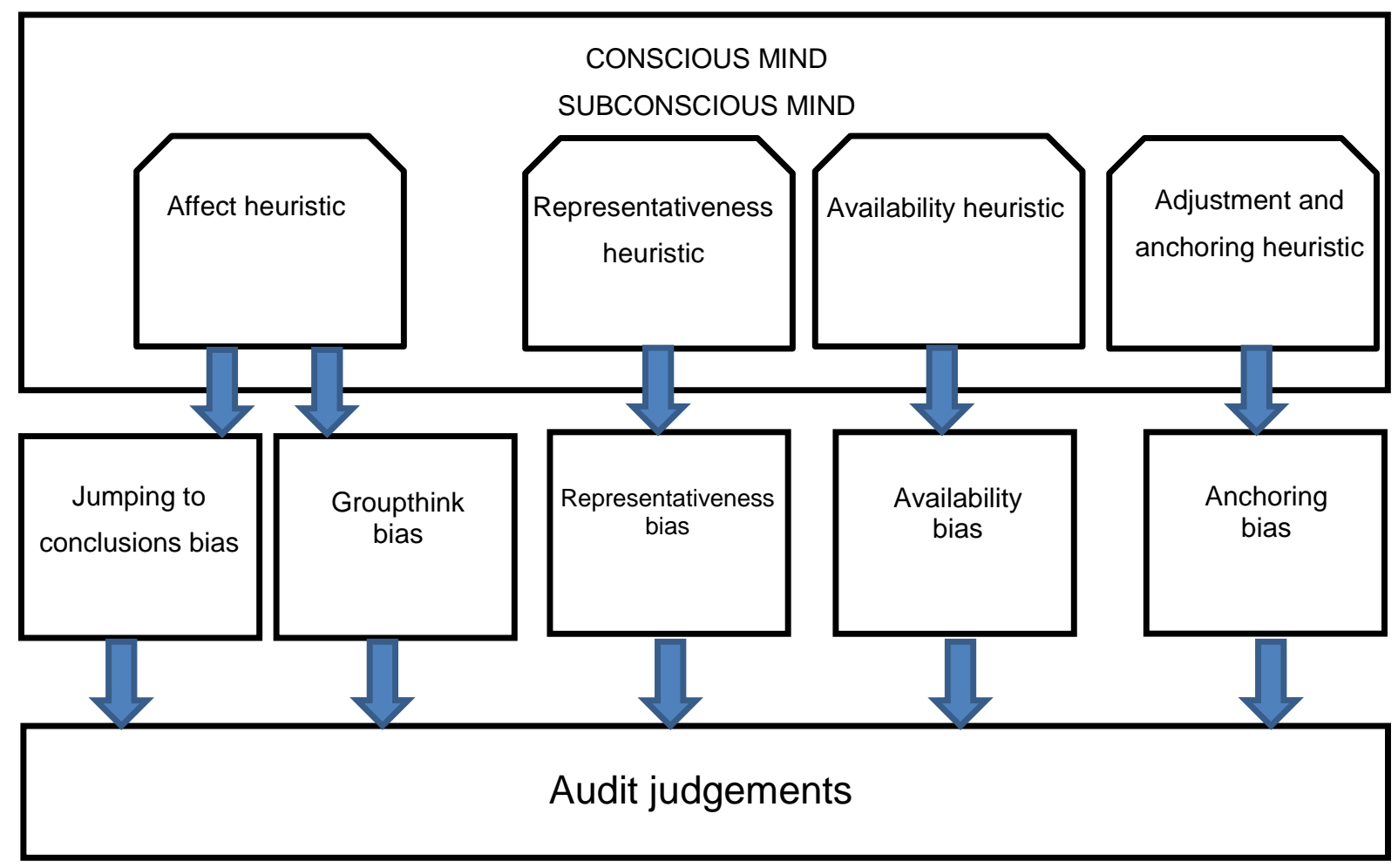

Figure 1. The Heuristic and Bias in Auditor Judgments

The analysis performed in this study further reveals that the use of mental shortcuts in making audit judgments are widespread in the auditing practice and is taught by more senior auditors to their juniors or new recruits. This raises an interesting question: do auditors know that they are influenced by biases when making professional judgements? The answer to this question is not conclusive. Some of the auditors interviewed in this study stated that they were aware of the risks of making inaccurate judgments, particularly when they had to make the judgements in a rush. They also asserted that they were aware of biases in professional judgements, but they did not specifically mention any types of biases that they thought might influence their judgments and decisions. The auditors argued that they had methods to overcome the possible biases. These methods include following a systematic way of making judgements, cross-verifying judgments across auditors, and use as much relevant information as possible when making judgements. Nevertheless, these so-called bias avoiding methods appear to be insufficient to overcome possible biases because the biases grow form heuristics that operate in auditors' subconscious minds. While some of the interviewed auditors were aware of judgement biases, other, on the other hand, admitted that they never thought that 
their approaches to making judgments might be flawed due to biases. These auditors were convinced that the ways they normally made judgements were the standard and acceptable way of making judgments as it was how they were taught since they entered the profession.

\section{CONCLUSION}

This study provides evidence of the existence of heuristics and biases in the professional judgements of auditors. That is, although auditing standards require auditors to formulate their judgements in a structured way, oftentimes auditors depart from a rational way of making judgements and, instead, rely on heuristics. These heuristics have led to systematic errors, or biases, in the judgements made by auditors when performing financial statements audit. There are five biases identified in this study that correspond to the four types of heuristics suggested in the literature. First, the jumping to conclusion bias, which grows from the affect heuristic, refers to auditors' propensity to make judgements based on limited evidence due to perceived situational pressure. Second, the groupthink bias, which also stems from the affect heuristic, refers to the auditors' tendency to suppress personal views on audit issues over the views of their group. Third, the representativeness bias, which originates from the representativeness heuristics, is characterised by auditors' overreliance on stereotypes or similarities to general norms when the auditors make judgements. Fourth, the availability bias, which develops from the availability heuristic, refers to auditors' propensity to make professional judgements by relying on available instances in their memories. Fifth, the anchoring bias, which originates from the adjustment and anchoring heuristic, denotes auditors' tendency to make judgments based on an initial point of reference and revise the initial judgements based on new information.

Apart from identifying the types of biases experienced by auditors, the results of this study also suggest that auditors differ in their level of awareness towards heuristics and biases. Some auditors have shown some awareness of mental shortcuts in judgement formulation and believe that they have had strategies to mitigate the adverse impact of heuristics in their judgements, even though these strategies are limited. Other auditors, nevertheless, do not realise that they have used heuristics when making judgements. Overall, the auditors in this study seem to lack attention to the possibly devastating impact of heuristics and biases on their professional judgements.

The results reported in this study provide significant theoretical contributions. Specifically, this study provides novel empirical evidence to support the application of the heuristic-bias framework in explaining the existence of biases in the judgements of auditors. This study also provides a new typology of audit judgement biases that can serve as a theoretical framework for studies examining heuristics and biases in the auditing context. Further, this study presents empirical evidence to support the notion that heuristics mostly work in the subconscious minds of individuals, even though they may also work in the conscious part of human minds.

A number of practical implications emerge from this study. First, the results imply that auditors cannot escape from the use of heuristics when making professional judgements, because these heuristics are used unconsciously by the auditors. As heuristics lead to judgement bias, unawareness of heuristics also mean that auditors are not aware of biases in their judgements. This should be of concern to auditors at public accounting firms. Auditors should be mindful of the temptation to make judgements using heuristics, follow the available judgement frameworks, and apply evaluation procedure to every judgement that they or their colleagues make during audit assignments. Further, the results showing that auditors lack awareness of heuristics and biases imply that most auditors use heuristics unconsciously. This should be of concern to professional accounting associations, academic institutions, and public accounting firms. These institutions should ensure their training or educational 
programs have included learning materials that aim to equip auditors, accountants, or accounting students with the knowledge about heuristics and biases and the skills needed to make high-quality judgements when heuristics are present.

The results of this study should be interpreted in light of its limitations. That is, while this study has identified the range of biases in audit judgements and the heuristics from which these biases originate, this study does not examine how these biases influence the quality of judgements made by auditors. Future studies could focus on this issue by specifically examine the effect of the five biases identified in this study on the quality or accuracy of auditors' judgements. Such research will provide further evidence of the consequences of heuristics and biases to the quality of auditing practices.

\section{REFERENCES}

Asbahr, K., \& Ruhnke, K. (2019). Real effects of reporting key audit matters on auditors' judgment and choice of action. International Journal of Auditing, 23(2), 165-180. https://doi.org/10.1111/ijau.12154

Bazerman, M. H., \& Moore, D. A. (2013). Judgmental in managerial decision making. Hoboken: John Wiley \& Sons.

Bettinghaus, B., Goldberg, S., \& Lindquist, S. (2014). Avoiding auditor bias and making better decisions. The Journal of Corporate Accounting \& Finance, 25(4), 39-44. https://doi.org/10.1002/jcaf.21953

Blumenthal-Barby, J. S. (2016). Biases and heuristics in decision making and their impact on autonomy. The American Journal of Bioethics, 16(5), 5-15. https://doi.org/10.1080/15265161.2016.1159750

Bonner, S. E. (2008). Judgment and decision making in accounting. New Jersey: Pearson Prentice Hall.

Bouteska, A., \& Regaieg, B. (2019). Psychology and behavioral finance: Anchoring bias by financial analysts on the Tunisian stock market. EuroMed Journal of Business, 15(1), 39-64. https://doi.org/10.1108/EMJB-08-2018-0052

Ceschi, A., Costantini, A., Sartori, R., Weller, J., \& Di Fabio, A. (2019). Dimensions of decision-making: An evidence-based classification of heuristics and biases. Personality and Individual Differences, 146, 188-200. https://doi.org/10.1016/j.paid.2018.07.033

Chang, C. J., \& Luo, Y. (2019). Data visualization and cognitive biases in audits. Managerial Auditing Journal, Forthcomin. https://doi.org/10.1108/MAJ-08-2017-1637

Choudhary, P., Merkley, K., \& Schipper, K. (2019). Auditors' quantitative materiality judgments: Properties and implications for financial reporting reliability. Journal of Accounting Research, 57(5), 1303-1351. https://doi.org/10.1111/1475-679X.12286

Cossette, P. (2014). Heuristics and cognitive biases in entrepreneurs: A review of the research. Journal of Small Business and Entrepreneurship, 27(5), 471-496. https://doi.org/10.1080/08276331.2015.1105732

Davidai, S., \& Gilovich, T. (2016). The headwinds/tailwinds asymmetry: An availability bias in assessments of barriers and blessings. Journal of Personality and Social Psychology, 111(6), 835-851. https://doi.org/10.1037/pspa0000066

Eutsler, J., Norris, A. E., \& Trompeter, G. M. (2018). A live simulation-based investigation: Interactions with clients and their effect on audit judgment and professional skepticism. Auditing: A Journal of Practice \& Theory, 37(3), 145-162. https://doi.org/10.2308/ajpt-51880 
Gao, P., \& Zhang, G. (2019). Auditing standards, professional judgment, and audit quality. The Accounting Review, 94(6), 201-225. https://doi.org/10.2308/accr-52389

Garber, M. D., Watkins, K. E., \& Kramer, M. R. (2019). Comparing bicyclists who use smartphone apps to record rides with those who do not: Implications for representativeness and selection bias. Journal of Transport and Health, 15, 1-14. https://doi.org/10.1016/j.jth.2019.100661

Gigerenzer, G., \& Gaissmaier, W. (2011). Heuristic decision making. Annual Review of Psychology, 62, 451-482. https://doi.org/10.1146/annurev-psych-120709-145346

Givi, J., \& Galak, J. (2019). The "future is now" bias: Anchoring and (insufficient) adjustment when predicting the future from the present. Journal of Experimental Social Psychology, 84. https://doi.org/10.1016/j.jesp.2019.103830

Guiral, A., Rodgers, W., Ruiz, E., \& Gonzalo-Angulo, J. A. (2015). Can expertise mitigate auditors' unintentional biases? Journal of International Accounting, Auditing and Taxation, 24, 105-117. https://doi.org/10.1016/j.intaccaudtax.2014.11.002

Hofstede, G., Hofstede, G. J., \& Minkov, M. (2010). Cultures and organizatios: Software of the Mind (3rd ed.). United States: McGraw-Hill.

Hussain, A., \& Oestreicher, J. (2018). Clinical decision-making: heuristics and cognitive biases for the ophthalmologist. Survey of Ophthalmology, 63(1), 119-124. https://doi.org/https://doi.org/10.1016/j.survophthal.2017.08.007

Institute of Chartered Accountants of Scotland (ICAS). (2012). A Professional Judgement Framework for Financial Reporting. ICAS.

International Auditing and Assurance Standards Board (IAASB). (2014). A Framework for Audit Quality: Key Elements that Create an Environment for Audit Quality. International Federation of Accountants (IFAC).

Jaspersen, J. G., \& Aseervatham, V. (2017). The Influence of affect on heuristic thinking in insurance demand. Journal of Risk and Insurance, 84(1), 239-266. https://doi.org/10.1111/jori.12088

Johnstone, K. M., Chen, J., \& Balzan, R. P. (2017). An investigation into the jumping-toconclusions bias in social anxiety. Consciousness and Cognition, 48, 55-65. https://doi.org/10.1016/j.concog.2016.10.012

Kadous, K., \& Zhou, Y. (Daniel). (2019). How does intrinsic motivation improve auditor judgment in complex audit tasks? Contemporary Accounting Research, 36(1), 108131. https://doi.org/10.1111/1911-3846.12431

Kahneman, D. (2011). Thinking, Fast and Slow. Penguin Books.

Kim, S., Mayorga, D. M., \& Harding, N. (2017). Can I interrupt you? Understanding and minimizing the negative effects of brief interruptions on audit judgment quality. International Journal of Auditing, 21(2), 198-211. https://doi.org/10.1111/ijau.12089

Knechel, W. R. (2013). Do auditing standards matter? Current Issues in Auditing, 7(2), 1-16. https://doi.org/10.2308/ciia-50499

Knechel, W. R. (2016). Audit quality and regulation. International Journal of Auditing, 20(3), 215-223. https://doi.org/10.1111/ijau.12077

Knechel, W. R., Krishnan, G. V., Pevzner, M., Shefchik, L. B., \& Velury, U. K. (2013). Audit quality: Insights from the academic literature. Auditing: A Journal of Practice \& Theory, 32(Supp. 1), 385-421. https://doi.org/10.2308/ajpt-50350

Lambert, T. A., \& Peytcheva, M. (2020). When is the averaging effect present in auditor judgments? Contemporary Accounting Research, 37(1), 277-296. https://doi.org/10.1111/1911-3846.12512

Lee, G., Barrowclough, C., \& Lobban, F. (2011). The influence of positive affect on jumping to conclusions in delusional thinking. Personality and Individual Differences, 50(5), 717-722. https://doi.org/10.1016/i.paid.2010.12.024 
Loock, M., \& Hinnen, G. (2015). Heuristics in organizations: A review and a research agenda. Journal of Business Research, 68(9), 2027-2036. https://doi.org/https://doi.org/10.1016/j.jbusres.2015.02.016

Lune, H., \& Berg, B. L. (2017). Qualitative Research Methods for the Social Sciences. Boston: Pearson.

Luo, G. Y. (2013). Can representativeness heuristic traders survive in a competitive securities market? Journal of Financial Markets, 16(1), 152-164. https://doi.org/10.1016/j.finmar.2012.05.001

Mactavish, C., McCracken, S., \& Schmidt, R. N. (2018). External auditors' judgment and decision making: An audit process task analysis. Accounting Perspectives, 17(3), 387-426. https://doi.org/10.1111/1911-3838.12182

Mala, R., \& Chand, P. (2015). Judgment and decision-making research in auditing and accounting: Future research implications of person, task, and environment perspective. Accounting Perspectives, 14(1), 1-50. https://doi.org/10.1111/1911$\underline{3838.12040}$

McLaughlin, K., Eva, K. W., \& Norman, G. R. (2014). Reexamining our bias against heuristics. Advances in Health Sciences Education, 19(3), 457-464. https://doi.org/10.1007/s10459-014-9518-4

Messier, W. F., Glover, S. M., \& Prawitt, D. F. (2019). Auditing \& Assurance Services: A Systematic Approach (11th ed.). United States: McGraw-Hill.

Miles, M. B., Huberman, A. M., \& Saldana, J. (2014). Qualitative Data Analysis: A Methods Sourcebook (3rd ed.). United States: Sage.

Nouri, P., Imanipour, N., Talebi, K., \& Zali, M. (2018). Most common heuristics and biases in nascent entrepreneurs' marketing behavior. Journal of Small Business \& Entrepreneurship, 30(6), 451-472. https://doi.org/10.1080/08276331.2018.1427406

Otuteye, E., \& Siddiquee, M. (2015). Overcoming cognitive biases: A heuristic for making value investing decisions. Journal of Behavioral Finance, 16(2), 140-149. https://doi.org/10.1080/15427560.2015.1034859

Patton, M. Q. (2015). Qualitative research \& evaluation methods: Integrating theory and practice (4th ed.). United States: Sage.

Sanusi, Z. M., Iskandar, T. M., Monroe, G. S., \& Saleh, N. M. (2018). Effects of goal orientation, self-efficacy and task complexity on the audit judgement performance of Malaysian auditors. Accounting, Auditing \& Accountability Journal, 31(1), 75-95. https://doi.org/10.1108/AAAJ-12-2015-2362

Schafer, B. A., \& Schafer, J. K. (2019). Interpersonal affect, accountability and experience in auditor fraud risk judgments and the processing of fraud cues. Advances in Accounting Behavioural Research, 22, 43-65. https://doi.org/10.1108/S1475148820190000022004

Sin, F. Y., Moroney, R. A., \& Strydom, M. (2015). Principles-based versus rules-based auditing standards: The effect of the transition from AS2 to AS5. International Journal of Auditing, 19(3), 282-294. https://doi.org/10.1111/ijau.12045

Slovic, P., Finucane, M. L., Peters, E., \& MacGregor, D. G. (2007). The affect heuristic. European Journal of Operational Research, 177(3), 1333-1352. https://doi.org/10.1016/j.ejor.2005.04.006

Tamir, D. I., \& Mitchell, J. P. (2013). Anchoring and adjustment during social inferences. Journal of Experimental Psychology: General, 142(1), 151-162. https://doi.org/10.1037/a0028232

Tsunogaya, N., Sugahara, S., \& Chand, P. (2016). Judgments of auditors on "principles" versus "guidance" in lease accounting standard. Asian Review of Accounting, 24(3), 362-386. https://doi.org/10.1108/ARA-04-2012-0017 
Tsunogaya, N., Sugahara, S., \& Chand, P. (2017). The impact of social influence pressures, commitment, and personality on judgments by auditors: Evidence from Japan. Journal of International Accounting Research, 16(3), 17-34. https://doi.org/10.2308/jiar-51761

Tversky, A., \& Kahneman, D. (1974). Judgment under uncertainty: Heuristics and biases. Science, 185(4157), 1124-1131. https://doi.org/10.1126/science.185.4157.1124

Wedemeyer, P. D. (2010). A discussion of auditor judgment as the critical component in audit quality - A practitioner's perspective. International Journal of Disclosure and Governance, 7(4), 320-333. https://doi.org/10.1057/jdg.2010.19

Xiao, H. (2020). Anchoring in international merger and acquisition equity decisions: evidence from Chinese firms. Baltic Journal of Management, 15(3), 395-410. https://doi.org/10.1108/BJM-04-2019-0124

Yang, L., Brink, A. G., \& Wier, B. (2018). The impact of emotional intelligence on auditor judgment. International Journal of Auditing, 22(1), 83-97. https://doi.org/10.1111/ijau.12106

Zhang, G., \& Zhu, A. X. (2019). A representativeness heuristic for mitigating spatial bias in existing soil samples for digital soil mapping. Geoderma, 351, 130-143. https://doi.org/10.1016/j.geoderma.2019.05.024 